\title{
Association between cardiometabolic comorbidities and Parkinson's disease in a Mexican population
}

\author{
Amin Cervantes-Arriaga ${ }^{1,2}$, Óscar Esquivel-Zapata², Emmanuel Escobar-Valdivia1, David García-Romero², \\ Ángel Alcocer-Salas ${ }^{2}$ and Mayela Rodríguez-Violante ${ }^{1,2 *}$ \\ ${ }^{1}$ Movement Disorders Clinic; ${ }^{2}$ Neurodegenerative Diseases Clinical Laboratory. Instituto Nacional de Neurología y Neurocirugía, Mexico City, Mexico
}

\begin{abstract}
Background: The prevalence of Parkinson's disease (PD) increases as the population ages. Studies have shown that some cardiometabolic comorbidities could be associated with risk or protection against developing PD. A retrospective case-control study was carried out to analyze the relationship between PD and cardiometabolic comorbidities. Material and methods: Subjects with $P D$ and controls without $P D$ were consecutively recruited. Data on type 2 diabetes mellitus, systemic arterial hypertension (SAH), dyslipidemia and body mass index were collected. Logistic regression analyses were carried out. Results: $A$ total of 781 subjects with PD (56.5\% males) and 1,000 controls (44.4\% males) were included. After adjusting for age and gender, SAH was found as an independent risk factor (OR: 1.32; 95\% Cl: 1.05-1.67; $p=0.02$ ), and obesity as a protective factor (OR: 0.72; 95\% Cl: 0.56-0.93; $p=0.01$ ). Conclusions: Subjects with $S A H$ had a higher risk of having PD, while obese subjects had a lower risk of having $P D$. The relationship between cardiometabolic disease, its treatment, and $P D$ etiopathogenesis appears to be extremely complex given the amount of contradictory data.
\end{abstract}

KEY WORDS: Body mass index. Diabetes mellitus. Dyslipidemia. Hypertension. Parkinson's disease. Risk.

\section{Asociación entre comorbilidades cardiometabólicas y enfermedad de Parkinson en población mexicana}

\section{Resumen}

Antecedentes: La prevalencia de la enfermedad de Parkinson (EP) aumenta a medida que la población envejece. Los estudios han demostrado que algunas comorbilidades cardiometabólicas pudieran estar asociadas con el riesgo o la protección de desarrollar la EP. Se realizó un estudio retrospectivo de casos y controles para analizar la relación entre la EP y las comorbilidades cardiometabólicas. Material y métodos: Se reclutaron sujetos con EP y controles sin EP de forma consecutiva. Se recolectaron datos sobre diabetes mellitus tipo 2, hipertensión arterial sistémica (HTA), dislipidemia e índice de masa corporal. Se llevó a cabo análisis de regresión logística. Resultados: Se incluyeron un total de 781 personas con EP (56,5\% hombres) y 1,000 controles (44,4\% hombres). Después de ajustar por edad y sexo, la HTA se encontró como factor de riesgo independiente (OR 1.32, IC 95\% 1.05-1.67, $p=0.02$ ) y la obesidad como factor protector (OR 0.72, IC 95\% 0.56-0.93, $p=0.01)$. Conclusiones: Los sujetos con HTA tienen un mayor riesgo de tener EP; mientras que los sujetos obesos tienen un menor riesgo de tener EP. La relación entre la enfermedad cardiometabólica, su tratamiento y etiopatogenia de la EP parece ser extremadamente compleja dada la cantidad de datos contradictorios.

PALABRAS CLAVE: Índice de masa corporal. Diabetes mellitus. Dislipidemia. Hipertensión. Enfermedad de Parkinson. Riesgo.

\footnotetext{
Correspondence:

Date of reception: 13-05-2021

*Mayela Rodríguez-Violante

E-mail: mrodriguez@innn.edu.mx

Gac Med Mex. 2021;157:624-629

Contents available at PubMed

www.gacetamedicademexico.com

0016-3813/@ 2021 Academia Nacional de Medicina de México, A.C.. Published by Permanyer. This is an open access article under the CC BY-NC-ND license (http://creativecommons.org/licenses/by-nc-nd/4.0/).
} 


\section{Introduction}

The prevalence of Parkinson's disease (PD) increases as the population ages. In Mexico, the incidence density reported between 2014 and 2017 was 9.48 per 100,000 person-years, which results in a public health problem 1 . PD pathophysiological mechanisms are not fully understood. Overlapping pathways, including mitochondrial abnormalities, neuroinflammation and protein aggregation, have been suggested to interact in the pathogenesis and development of the disease ${ }^{2}$.

Interaction between different environmental and genetic factors could significantly contribute to the development of $\mathrm{PD}^{3}$. There is current evidence that suggests that some comorbidities could be associated with risk of PD or protection against its development ${ }^{4,5}$. Among these, the main cardiometabolic risk factors have awaken great interest.

Factors that favor a pro-inflammatory state and altered free radical metabolism converge on mitochondrial dysfunction, with neurodegeneration being linked to insulin resistance in a common pathway 6 .

Type 2 diabetes mellitus (T2DM) has been associated not only to the risk of developing PD, but also as a modifying factor in the progression and natural history of the disease $e^{7,8}$. In addition, most epidemiological studies, although not all, have reported an association between T2DM and a higher risk of $\mathrm{PD}^{9-11}$.

Epidemiological studies addressing the association between systemic arterial hypertension (SAH) and PD have been conflicting, with some studies identifying $\mathrm{SAH}$ as a risk and others as a protective factor ${ }^{12,13}$. Similarly, dyslipidemia has been a controversial issue as to whether it is a risk or protective factor for $\mathrm{PD}^{13,14}$. Finally, the association between body mass index (BMI) and PD has not been conclusive either. Some studies suggest that there is no significant relationship between $\mathrm{BMI}$ and the development of $\mathrm{PD}^{15,16}$. On the other hand, other studies, including meta-analyses, have shown that both overweight and low BMI could be a relevant risk factor ${ }^{17-19}$.

Establishing the interaction of pathologies is a relevant starting point for identifying possible areas of intervention. With population aging, the prevalence of cardiometabolic and neurodegenerative pathologies is going to increase.

The purpose of this case-control study is to evaluate the relationship between PD and the main cardiometabolic comorbidities in a sample from Latin America in order to enrich current knowledge.

\section{Materials and methods}

Consecutive patients diagnosed with PD using the Movement Disorders Society Clinical Diagnostic Criteria for Parkinson's ${ }^{20}$ disease were included for this study, which was carried out at the Movement Disorders Clinic of the National Institute of Neurology and Neurosurgery (Mexico City, Mexico) between 2016 and 2019. Subjects with secondary hypertension, pancreatic disease, hypothyroidism or hyperthyroidism, or any type of kidney disease were excluded.

The controls, aged 50 years or older, were recruited from the outpatient clinic waiting room. All subjects agreed to participate and granted signed consent. The same exclusion criteria were considered for the control group. In addition, personal or first-degree family history of neurological or neuropsychiatric disease were also considered as exclusion criteria for this group.

Cardiometabolic history evaluation was recorded using a semi-structured questionnaire that consisted of several parts. First, sociodemographic variables were collected, which included age and gender. All subjects were questioned about known T2DM diagnosis, disease duration, and any glucose-lowering treatment. The second part evaluated the presence of a $\mathrm{SAH}$ diagnosis, disease duration and any antihypertensive treatment. On next part, dyslipidemia diagnosis, including disease duration and use of lipid-lowering drugs was evaluated. If the subjects were taking a glucose-lowering, antihypertensive or lipid-lowering drug without a known indication, the medical history was examined in depth in order to find out the indication. Subjects taking any of these drugs for no known reason were excluded. If necessary, subjects were provided a complete list of medications to help them remember the name of the drug.

The last part evaluated anthropometric variables, including height (in meters) and weight (in kilograms) for BMI calculation. Subjects were categorized according to their BMI into underweight, normal weight, overweight and obesity according to international standards.

The study protocol was approved by the local ethics committee (121/19) and all participants granted written informed consent.

\section{Statistical analysis}

The Kolmogorov-Smirnov test was used to test for normality. All variables of interest had a 
non-parametric distribution. For the comparison of quantitative variables, Mann-Whitney's U-test was used. Qualitative variables were evaluated using the chi-square test. Variables with statistically significant differences in the bivariate analysis were included in the multivariate analysis.

For the logistic regression analyses, the presence of PD was defined as a dependent variable. Simple logistic regression was used to estimate the odds ratios (OR) for each independent variable, followed by a multivariate stepwise logistic regression. The Hosmer-Lemeshow test was used to determine the goodness of fit. A $p$-value $<0.05$ was established for statistical significance. Statistical analyses were carried out with SPSS, version 17 (SPSS Inc., Chicago, IL, USA).

\section{Results}

A total of 781 subjects with PD (56.5\% males) and 1,000 controls ( $44.4 \%$ males) were included. Table 1 shows a thorough comparison of the main variables between both groups.

$\mathrm{SAH}$ and dyslipidemia were more common in the PD group in comparison with controls. No statistically significant difference was found in the prevalence of T2DM between groups, although T2DM was somewhat more common and showed a tendency towards statistical significance in the PD group. Finally, subjects with PD had lower BMI in comparison with controls. In the PD group, normal weight was more common in comparison with controls. On the other hand, obesity was more common in controls than in the PD group.

In the bivariate analysis, using simple logistic regression, SAH (OR: 1.62; 95\% confidence interval $[\mathrm{Cl}]$ : 1.31-2.01; $p<0.001$ ) and dyslipidemia (OR: 1.31; 95\% Cl: $1.01-1.70 ; p=0.03$ ) were found to be risk factors for PD. On the other hand, the presence of obesity was shown to be a protective factor against PD (OR: 0.72; 95\% Cl: 0.56-0.93; $p=0.01$ ). In addition, the female gender was also shown to be a protective factor (OR: 0.61; 95\% Cl: 0.51-0.74; $\mathrm{p}<0.001$ ).

After adjusting for age and gender in the multivariate analysis, only SAH persisted as an independent risk factor (OR: 1.32; 95\% Cl: 1.05-1.67; $\mathrm{p}=0.02$ ) and obesity remained a protective factor (OR: 0.72; $95 \%$ Cl: $0.56-0.93 ; p=0.01)$. Table 2 shows a full description of the model. The presence of T2DM was included in the model owing to theoretical foundations, although statistical significance was not reached in the bivariate analysis.
Table 1. Comparison of the main variables between controls and subjects with Parkinson's disease (PD)

\begin{tabular}{|c|c|c|c|}
\hline & Controls & PD & \multirow[t]{2}{*}{ p } \\
\hline & $(n=1,000)$ & $(n=781)$ & \\
\hline \multicolumn{4}{|l|}{ Gender } \\
\hline Males n (\%) & $444(44.4)$ & $442(56.6)$ & $<0.001^{*}$ \\
\hline Females n (\%) & $556(55.6)$ & $339(43.4)$ & $<0.001^{*}$ \\
\hline \multicolumn{4}{|l|}{ Age } \\
\hline Mean \pm SD & $57.8 \pm 15.4$ & $62.9 \pm 13.2$ & $<0.001^{\dagger}$ \\
\hline \multicolumn{4}{|l|}{ Diagnoses } \\
\hline Diabetes mellitus & $132(13.2 \%)$ & $128(16.4 \%)$ & $0.06^{\star}$ \\
\hline Hypertension & $225(22.5 \%)$ & $250(32 \%)$ & $<0.01-$ \\
\hline Dyslipidemia & $141(14.1 \%)$ & $139(17.8 \%)$ & $0.03-$ \\
\hline \multicolumn{4}{|l|}{ BMl } \\
\hline Mean \pm SD & $27.1 \pm 4.8$ & $26.5 \pm 4.8$ & $<0.01^{\dagger}$ \\
\hline Normal (\%) & $325(32.5 \%)$ & $292(37.4 \%)$ & $0.03^{*}$ \\
\hline Underweight (\%) & $16(1.6 \%)$ & $20(2.6 \%)$ & $0.15^{\star}$ \\
\hline Overweight (\%) & $401(40.1 \%)$ & $302(38.7 \%)$ & $0.54^{*}$ \\
\hline Obesity (\%) & $258(25.8 \%)$ & $167(21.4 \%)$ & $0.03^{*}$ \\
\hline
\end{tabular}

${ }^{*}$ Chi-square test.

†Mann-Whitney's U-test.

BMI: body mass index; SD: standard deviation.

\section{Discussion}

This is the first Mexican case-control study to evaluate the association of the main cardiometabolic comorbidities with PD. Our study did not find a different proportion of T2DM in PD patients in comparison with controls, although a tendency was observed. On the other hand, the PD group was found to have a slightly but significantly different profile in other cardiometabolic risk factors in comparison with the general population. The PD group had a higher frequency of SAH and dyslipidemia, and a lower frequency of obesity.

In this regard, our study contrasts with some published epidemiological data based on prospective studies that have reported a higher risk of PD in patients with T2DM. In this sense, a meta-analysis published by Yue et al. showed that prospective studies conducted in different populations can significantly vary ${ }^{9}$. For example, a retrospective study from Taiwan and prospective studies from the US and Finland reported a risk increase. On the other hand, other prospective studies from Spain and the US failed to replicate these results. In addition, a retrospective Japanese study showed a protective effect of 0.38 for $\mathrm{T}^{2} \mathrm{DM}^{13}$. In general, this evidence suggests that ethnicity may play an important role. Study design also appears to play an important role. A more recent meta-analysis showed that cohort studies provided 
Table 2. Logistic regression model using Parkinson's disease as a dependent variable

\begin{tabular}{|c|c|c|c|c|c|c|}
\hline \multicolumn{2}{|c|}{ Model } & \multirow{2}{*}{$\begin{array}{c}\text { B } \\
0.024\end{array}$} & \multirow{2}{*}{$\begin{array}{c}\operatorname{Exp}(\mathrm{B}) \\
1.024\end{array}$} & \multicolumn{2}{|c|}{$95 \% \mathrm{Cl}$} & \multirow{2}{*}{$\begin{array}{c}p \\
<0.001\end{array}$} \\
\hline 1 & Age & & & 1.024 & 1.018 & \\
\hline & Female gender & -0.483 & 0.617 & 0.617 & 0.509 & $<0.001$ \\
\hline \multirow[t]{3}{*}{2} & Age & 0.022 & 1.022 & 1.015 & 1.029 & $<0.001$ \\
\hline & Female gender & -0.487 & 0.615 & 0.507 & 0.745 & $<0.001$ \\
\hline & $\mathrm{SAH}$ & 0.281 & 1.324 & 1.058 & 1.657 & 0.014 \\
\hline \multirow[t]{4}{*}{3} & Age & 0.021 & 1.022 & 1.014 & 1.029 & $<0.001$ \\
\hline & Female gender & -0.486 & 0.615 & 0.508 & 0.745 & $<0.001$ \\
\hline & $\mathrm{SAH}$ & 0.272 & 1.313 & 1.047 & 1.645 & 0.018 \\
\hline & T2DM & 0.092 & 1.097 & 0.835 & 1.441 & 0.507 \\
\hline \multirow[t]{5}{*}{4} & Age & 0.021 & 1.021 & 1.014 & 1.029 & $<0.001$ \\
\hline & Female gender & -0.491 & 0.612 & 0.505 & 0.741 & $<0.001$ \\
\hline & SAH & 0.254 & 1.289 & 1.026 & 1.62 & 0.029 \\
\hline & T2DM & 0.088 & 1.092 & 0.831 & 1.435 & 0.529 \\
\hline & Dyslipidemia & 0.143 & 1.154 & 0.884 & 1.506 & 0.293 \\
\hline \multirow[t]{9}{*}{5} & Age & 0.02 & 1.02 & 1.013 & 1.028 & $<0.001$ \\
\hline & Female gender & -0.491 & 0.612 & 0.505 & 0.742 & $<0.001$ \\
\hline & $\mathrm{SAH}$ & 0.281 & 1.324 & 1.052 & 1.666 & 0.017 \\
\hline & T2DM & 0.102 & 1.108 & 0.841 & 1.458 & 0.466 \\
\hline & Dyslipidemia & 0.17 & 1.186 & 0.907 & 1.551 & 0.213 \\
\hline & BMI & & & & & 0.033 \\
\hline & Underweight & 0.376 & 1.457 & 0.728 & 2.917 & 0.288 \\
\hline & Overweight & -0.184 & 0.832 & 0.665 & 1.04 & 0.106 \\
\hline & Obesity & -0.329 & 0.72 & 0.555 & 0.933 & 0.013 \\
\hline
\end{tabular}

BMI: body mass index; Cl: confidence interval; SAH: systemic arterial hypertension; T2DM: type 2 diabetes mellitus.

strong evidence (OR: 1.29) that T2DM was associated with a higher risk of PD; on the other hand, case-control studies showed an inverse association between T2DM and PD (OR: 0.51) ${ }^{8}$. In our study, T2DM was somewhat more common in the PD group but without statistical significance being reached despite the fact that it was a case-control study. To the best of our knowledge, this is the first report on the Latin American population and deserves further investigation.

There are few epidemiological studies addressing the association between $\mathrm{SAH}$ and PD, with results ranging from no association ${ }^{10}$ to being a protective factor $^{13}$. A recent meta-analysis by Hou et al. reported an association of preexisting SAH with a higher risk for developing $\mathrm{PD}^{12}$. Interestingly, a sub-analysis based on ethnic characteristics showed that most part of the risk effect was attributable to Asian studies, while little or no association was more common in Caucasian population studies. In this regard, our study adds to current knowledge by including $\mathrm{SAH}$ as an independent risk factor in a Latin American sample.

It is possible for the relationship between SAH and PD not to be direct. The use of propranolol has been associated with a higher risk of $\mathrm{PE}^{21,22}$. Strangely enough, a recent study reported a protective effect of beta-blockers against the appearance of PD in non-diabetic patients, but the opposite in diabetic patients with $\mathrm{PD}^{23}$.

As for dyslipidemia, our study found no statistically significant risk after adjusting for other variables. Our findings are in line with the retrospective study carried out by Yang et al. ${ }^{10}$. As in the case of SAH and beta-blockers, the association with dyslipidemia could be more related to the use of statins rather than to blood lipid levels. Jeong et al. reported that statin use was associated with an increased risk of $\mathrm{PD}^{19}$. On the other hand, a recent meta-analysis showed that atorvastatin appears to reduce the risk of $\mathrm{PD}^{24}$. Interactions between cardiometabolic comorbidities, glucose-lowering drugs, statins and blood-lowering agents remain a difficult-to-elucidate issue.

Finally, the association of BMI with PD was not conclusive either. Longitudinal studies do not suggest a significant relationship between $\mathrm{BMI}$ and the development of $P D^{19,20}$. Meta-analyses have been conflicting, with both overweight and low BMI being reported as risk factors ${ }^{15,16}$. The most notable limitation of these studies is that normal weight and underweight individuals were grouped together, and assessing underweight as a possible independent risk factor was therefore not possible. A study on this topic that used a Korean national database found a risk for PD of 1.28 in the underweight group, in comparison with subjects with normal $\mathrm{BMI}^{23}$. On the other hand, the same study reported a possible protective effect for the overweight group, similar to our findings.

Our study has several limitations. First, subjects in the PD group were older. Not only is age the most important risk factor for PD, but this may also be true for all cardiometabolic comorbidities. In addition, a difference was found with regard to gender, with fewer women in the PD group. Although this is in line with epidemiological studies that report a higher 
prevalence of $P D$ in men, especially in the group aged 50 to 59 years, ${ }^{25}$ we cannot rule out a selection bias, with women being more prone to participate in the control group. Given the large sample size, a gender- and age-matched control study would have been difficult to achieve. However, the regression model was adjusted for these two variables and both $\mathrm{SAH}$ and obesity maintained statistical significance. Second, the chronological relationship between the appearance of comorbidities and the appearance of PD was not evaluated. In this regard, it can be argued that the time of diagnosis may not really be the time of onset of any of these evaluated diseases. PD prodromal phase can last up to one decade ${ }^{26}$, but T2DM, SAH and dyslipidemia can also remain undiagnosed for years, in spite of oxidative stress and chronic inflammation being present. Identifying actual onset of the disease, not its diagnosis, requires the use of specific biomarkers throughout time. Third, a self-reported diagnosis and broad operational definitions were used to define the presence or absence of all comorbidities that are susceptible to recall bias. In addition, no blood tests were carried out; therefore, cardiometabolic risk control could not be assessed.

\section{Conclusions}

Subjects with SAH had a higher risk of PD, while obesity provided a lower risk of having PD. The relationship between cardiometabolic disease, its treatment and PD etiopathogenesis appears to be extremely complex given the amount of conflicting data. A prospective cohort study evaluating preclinical biomarkers for both cardiometabolic disease and $P D$ is required for our findings to be confirmed.

\section{Funding}

No funding was required for this study.

\section{Conflict of interests}

The authors declare that they have no conflicts of interest.

\section{Ethical disclosures}

Protection of human and animal subjects. The authors declare that the procedures that were followed adhered to the ethical standards of the responsible committee for experimentation on human beings and were in agreement with the World Medical Association and the Declaration of Helsinki.

Confidentiality of data. The authors declare that they have followed the protocols of their work center on the publication of patient data.

Right to privacy and informed consent. The authors have obtained informed consent from the patients and/or subjects referred to in the article. This document is in the possession of the corresponding author.

\section{References}

1. Rodríguez-Violante M, Velásquez-Pérez L, Cervantes-Arriaga A. Incidence rates of Parkinson's disease in Mexico: Analysis of 2014-2017 statistics. Rev Mex Neurocien. 2019;20:136-40.

2. Aviles-Olmos I, Limousin P, Lees A, Foltynie T. Parkinson's disease, insulin resistance and novel agents of neuroprotection. Brain. 2012;136:374-84.

3. Schapira AH, Jenner P. Etiology and pathogenesis of Parkinson's disease. Mov Disord. 2011;26:1049-55.

4. Tysnes OB, Storstein A. Epidemiology of Parkinson's disease. J Neural Transm (Vienna). 2017:124:901-5.

5. Ascherio A, Schwarzschild MA. The epidemiology of Parkinson's disease: risk factors and prevention. Lancet Neurol. 2016;15:1257-72.

6. Athauda D, Foltynie T. Insulin resistance and Parkinson's disease: A new target for disease modification? Prog Neurobiol. 2016;145146:98-120.

7. Ong M, Foo H, Chander RJ, Wen MC, Au WL, Sitoh YY, et al. Influence of diabetes mellitus on longitudinal atrophy and cognition in Parkinson's disease. J Neurol Sci. 2017;377:122-6.

8. Chohan H, Senkevich K, Patel RK, Bestwick JP, Jacobs BM, Bandres Ciga S, et al. Type 2 diabetes as a determinant of Parkinson's disease risk and progression. Mov Disord. 2021;36(6):1420-9.

9. Yue X, Li H, Yan H, Zhang P, Chang L, Li T. Risk of Parkinson disease in diabetes mellitus: An updated meta-analysis of population-based cohort studies. Medicine (Baltimore). 2016:95:e3549.

10. Yang YW, Hsieh TF, Li Cl, Liu CS, Lin WY, Chiang JH, et al. Increased risk of Parkinson disease with diabetes mellitus in a population-based study. Medicine (Baltimore). 2017:96:e5921.

11. De Pablo-Fernandez E, Goldacre R, Pakpoor J, Noyce AJ, Warner TT. Association between diabetes and subsequent Parkinson disease: A record-linkage cohort study. Neurology. 2018;91:e139-e142.

12. Hou L, Li Q, Jiang L, Qiu H, Geng C, Hong JS, et al. Hypertension and diagnosis of Parkinson's disease: A meta-analysis of cohort studies. Front Neurol. 2018;9:162.

13. Miyake $Y$, Tanaka K, Fukushima W, Sasaki S, Kiyohara C, Tsuboi $Y$, et al. Case-control study of risk of Parkinson's disease in relation to hypertension, hypercholesterolemia, and diabetes in Japan. J Neurol Sci. 2010;293:82-6.

14. Jeong SM, Jang W, Shin DW. Association of statin use with Parkinson's disease: Dose-response relationship. Mov Disord. 2019;34:1014-21.

15. Roos E, Grotta A, Yang F, Bellocco R, Ye W, Adami HO, et al. Body mass index, sitting time, and risk of Parkinson disease. Neurology. 2018;90:e1413-e1417

16. Palacios N, Gao X, McCullough ML, Jacobs EJ, Patel AV, Mayo T, et al. Obesity, diabetes, and risk of Parkinson's disease. Mov Disord. 2011;26:2253-9.

17. Chen J, Guan Z, Wang L, Song G, Ma B, Wang Y. Meta-analysis: overweight, obesity, and Parkinson's disease. Int J Endocrinol. 2014:2014:203930.

18. Wang Y, Wang Y, Li J, Zhang Y, Yin H, Han B. Body mass index and risk of Parkinson's disease: A dose-response meta-analysis of prospective studies. PLoS One 2015;10:e0131778.

19. Jeong S, Han K, Kim D, Rhee S, Jang W, Shin D. Body mass index, diabetes, and the risk of Parkinson's disease. Mov Disord. 2019:35:236-44.

20. Postuma RB, Berg D, Stern M, Poewe W, Olanow CW, Oertel W, et al. MDS clinical diagnostic criteria for Parkinson's disease. Mov Disord. 2015;30:1591-601. 
21. Gronich N, Abernethy D, Auriel E, Lavi I, Rennert G, Saliba W. ß2-adrenoceptor agonists and antagonists and risk of Parkinson's disease. Mov Disord. 2018;33:1465-71.

22. Koren G, Norton G, Radinsky K, Shalev V. Chronic use of $\beta$-blockers and the risk of Parkinson's disease. Clin Drug Investig. 2019;39:463-8.

23. de Germay S, Conte C, Rascol O, Montastruc J, Lapeyre-Mestre M. $\beta$-adrenoceptor drugs and Parkinson's disease: A nationwide nested case-control study. CNS Drugs. 2020;34:763-72.
24. Yan J, Qiao L, Tian J, Liu A, Wu J, Huang J, et al. Effect of statins on Parkinson's disease: A systematic review and meta-analysis. Medicine (Baltimore). 2019;98:e14852.

25. Pringsheim T, Jette N, Frolkis A, Steeves TD. The prevalence of Parkinson's disease: a systematic review and meta-analysis. Mov Disord. 2014;29:1583-90.

26. Postuma RB, Berg D. Prodromal Parkinson's disease: The decade past, the decade to come. Mov Disord. 2019;34:665-75. 